\title{
Trypanosoma vivax is the second leading cause of camel trypanosomosis in Sudan after Trypanosoma evansi
}

\author{
Ehab Mossaad ${ }^{1,2^{*}}$, Bashir Salim³ ${ }^{3}$ Keisuke Suganuma ${ }^{2,4}$, Peter Musinguzi ${ }^{2}$, Mohammed A. Hassan $^{5}$, E. A. Elamin ${ }^{3}$,
} G. E. Mohammed ${ }^{1}$, Amel O. Bakhiet ${ }^{1}$, Xuenan Xuan ${ }^{2,4}$, Rawan A. Satti ${ }^{1}$ and Noboru Inoue ${ }^{6}$

\begin{abstract}
Background: This study was conducted in response to recurring reports from eastern Sudan of camel trypanosomosis that can no longer be treated by currently available trypanocidal drugs. One hundred and eighty-nine blood samples were obtained from camels in different herds and local markets in the western part of Sudan, and a cross-sectional study was carried out between December 2015 and February 2016 to identify the causative agents and possible circulating genotypes.

Results: The prevalence of trypanosomes detected using the conventional parasitological techniques of Giemsa-stained blood smears, wet blood smears and the microhematocrit centrifugation technique (MHCT) was $7 \%(13 / 189), 11 \%(21 / 189)$ and 19\% (36/189), respectively. However, a multi-species KIN-PCR targeting the ITS region revealed that the prevalence of Trypanosoma evansi was 37\% (70/189), while that of T. vivax was $25 \%$ (47/189). Consequently, we used a T. evansi-specific PCR (RoTat1.2 VSG gene) to analyse the KIN-PCR-positive samples and a T. vivax-specific PCR (Cathepsin L-like gene) to analyse all of the samples. The prevalence of T. evansi was $59 \%$ (41/70), while the prevalence of T. vivax was 31\% (59/189). Mixed infections were detected in 18\% (34/189) of the samples. These results were further confirmed by sequencing and a phylogenetic analysis of the complete internal transcribed spacer (ITS) region of T. evansi and the TviCatL gene of T. vivax.

Conclusion: We conclude that T. vivax was newly introduced to the camel population and that T. evansi is no longer the single cause of camel trypanosomosis in Sudan. The presence of T. vivax in camels detected in this study is a challenge in the choice of diagnostic approaches, particularly serology, and PCRs. However, an analysis of drug resistance should be performed, and the genotypic variation should be verified. To our knowledge, this is the first molecular study on T. vivax and mixed-infection with T. vivax and T. evansi in Sudanese camels.
\end{abstract}

Keywords: Dromedary camels, Sudan, Trypanosomosis, Trypanosoma evansi, Trypanosoma vivax

\section{Background}

With 4,623,000 camels (Camelus dromedaries), Sudan has the second largest camel population in the world after Somalia (FAO and the Annual Report of the Ministry of Animal Resources, Fisheries and Ranges, 2010). These dromedaries, which are sustainably used in arid and

\footnotetext{
* Correspondence: ehabmssd7@gmail.com

'Department of Pathology, Parasitology and Microbiology, College of Veterinary Medicine, Sudan University of Science and Technology, P.O. Box 204, Khartoum, Sudan

${ }^{2}$ National Research Center for Protozoan Diseases, Obihiro University of Agriculture and Veterinary Medicine, Obihiro, Hokkaido 080-8555, Japan Full list of author information is available at the end of the article
}

hostile environments, provide food and transport for millions of people in the marginal agricultural areas of Sudan and throughout the world. Trypanosomosis, which is caused by Trypanosoma evansi, a parasite that infects livestock and a potential human pathogen, is a major threat to these valuable animals $[1,2]$. Trypanosoma evansi has multiple and complex means of transmission depending on the host and the geographical area. Biting and sucking insects transmit the parasite mechanically and the transmission can be vertical, horizontal, iatrogenic, or per-oral, each of which has different epidemiological significance depending on the season, location, and 
host species [3]. In Sudan, cattle, sheep and goats undergo protracted infection in which they may play the role of a reservoir host [4]. In addition, co-herding may increase the possibility of infection with $T$. evansi and other trypanosomes [5].

Clinical signs and pathological lesions are unreliable for definitively diagnosing these infections in camels [6]. Parasitological examinations suffer from limited sensitivity $[7,8]$ and serological tests cannot distinguish between past and current infections as the antibodies persist in the circulation [8].

In Sudan, the disease known as "Guffar" is a serious protozoan disease of camels. The disease was first reported in the country in $1904[5,9]$. Since then, various studies have used parasitological and serological tests to investigate the epidemiology of camel trypanosomosis in different parts of the country [4,10-13]. Very recently, a few reports have described the performance of molecular studies [14-16].

To date, all of the reports on camel trypanosomosis in Sudan have indicated that T. evansi is the sole pathogenic trypanosome infecting camels [12, 13, 15, 16]; no other Trypanosoma spp. have been documented thus far. To this end, we conducted the present study in response to recurring reports from eastern Sudan of camel trypanosomoses that no longer respond to the currently available trypanocidal drugs. We aimed to obtain information on the current prevalence of the disease as well as identify the causative agents and possible genotypes circulating in the area.

\section{Methods}

\section{Study area and sample collection}

Samples were obtained from 189 camels from three herds in Wd-Alhlio, Alshagrab and Khor Wd-Omer, which are located around El-Showak in Kassala state $(n=148)$, and from Tumbool market (at a camel slaughterhouse) in El-Gazira state $(n=41)$ where camels are brought from western Sudan, across the natural barrier of the River Nile (see map in Fig. 1). After obtaining the consent of the camels' owners, $3 \mathrm{ml}$ of blood was drawn from the jugular vein into vacutainer tubes with EDTA (Terumo, Tokyo, Japan). The samples were labelled with a unique code and were placed in a cool box at $4{ }^{\circ} \mathrm{C}$ until they were transported to the laboratory.

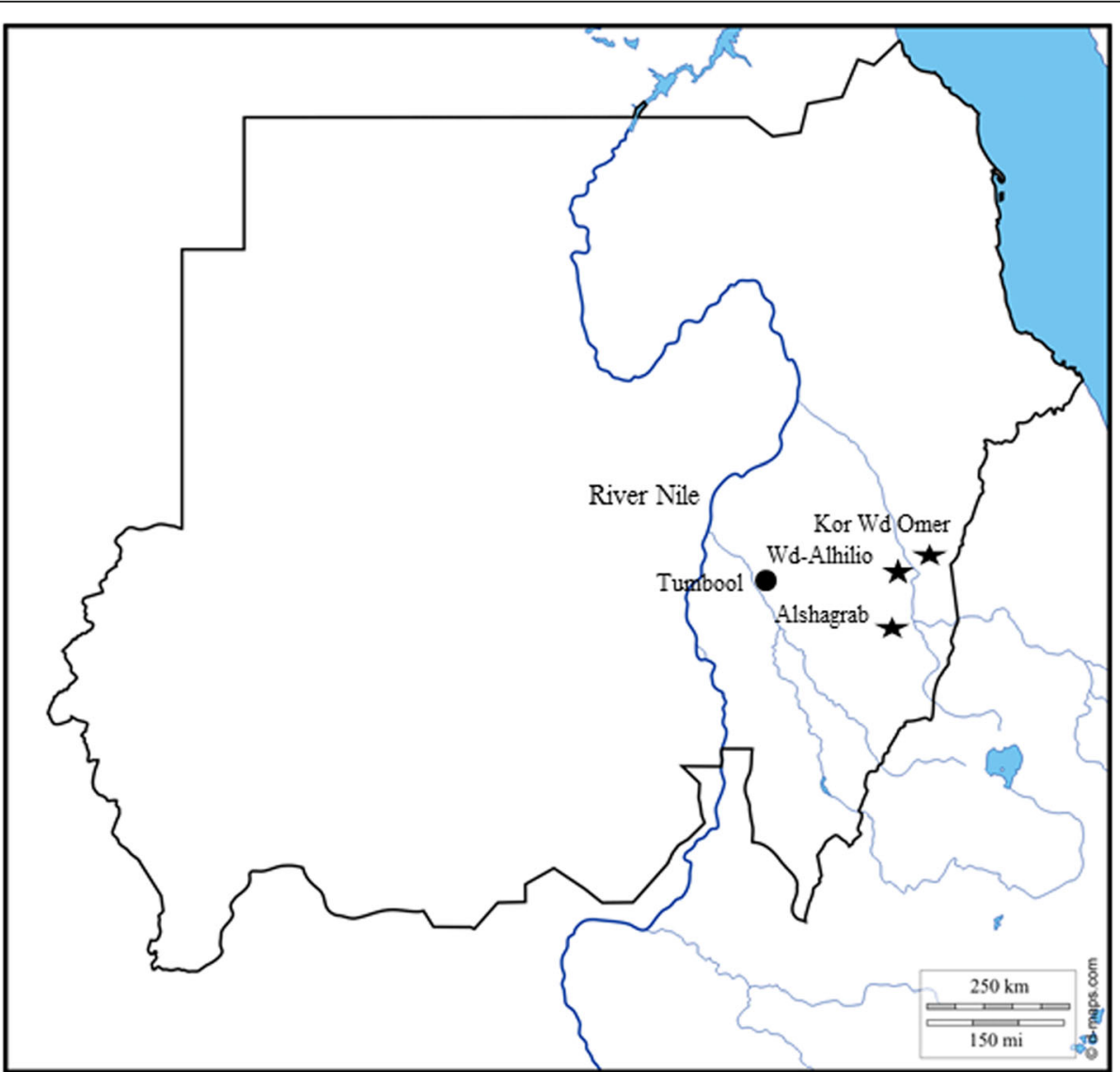

Fig. 1 A map of Sudan: The locations of the sampling areas from different herds are shown with black stars. The black dot indicates Tumbool slaughterhouse. Source: http://www.d-maps.com/carte.php?num_car=1310\&lang=en. With some modifications 


\section{Conventional parasitological examinations}

All the blood samples were examined in situ for the presence of trypanosome species using wet blood films [17], the microhaematocrit centrifugation technique (MHCT), the packed cell volume (PCV) technique described by Mamoudou et al. [18] and 10\% Giemsa thin blood smears, according to the methods of Murray et al. [17], and the OIE guidelines [19].

\section{DNA extraction and the PCR-based identification of the trypanosome species}

Genomic DNA was extracted from all blood samples using a QIAamp DNA Blood Mini Kit (Qiagen, Hilden, Germany), in accordance with the manufacturer's instructions, and four different PCR reactions were employed to detect and identify trypanosome DNA in camels. These included: (i) a KIN-multi species PCR, which amplifies the internal transcribed spacer 1 (ITS1) and allows for the simultaneous detection of three major trypanosome species ( $T$. evansi, $T$. congolense and $T$. vivax) [20]; (ii) the RoTat 1.2 VSG PCR (T. evansi type A-specific), which specifically amplifies the RoTat 1.2 VSG gene encoding the variable surface glycoprotein (VSG) of T. evansi [21]; (iii) the TviCatL PCR, which amplifies the Cathepsin L-like gene, which is highly conserved among T. vivax isolates [22]; and (iv) the internal transcribed spacers (ITS), which are versatile genetic markers that are used for phylogenetic analyses, the evaluation of the evolutionary process and for the determination of taxonomic identities [23, 24]. All the primer sequences used in the PCRs are listed in Table 1. Trypanosomes were detected using single-step PCR methods with a total reaction volume of $10 \mu \mathrm{l}$, which included $1 \mu \mathrm{l}$ of $10 \times$ reaction buffer, $0.3 \mu \mathrm{l}$ of $50 \mathrm{mM}$ magnesium chloride, $1 \mu \mathrm{l}$ of $250 \mu \mathrm{M}$ dNTPs, $0.1 \mu \mathrm{l}$ of Taq DNA polymerase (Invitrogen ${ }^{\text {tw }}$, Thermo Fisher Scientific Inc., MA, USA), $1 \mu \mathrm{l}$ each of $10 \mathrm{mM}$ forward and reverse primers, $4.6 \mu \mathrm{l}$ of double-distilled water and $1 \mu \mathrm{l}$ of the DNA sample, which was added to the individual
PCR mixtures. PCRs were conducted on a Veriti ${ }^{\text {Tw }}$ Thermal Cycler (Thermo Fisher Scientific). The PCR conditions that were used for the KIN-PCR and the TviCatLPCR were previously described by Laohasinnarong et al. [25], while the conditions of the RoTat 1.2 VSG-PCR were described by Urakawa et al. [21]. The PCR products were electrophoresed in $2 \%$ agarose gels, stained with ethidium bromide, and visualised under ultraviolet light.

\section{Cloning and DNA sequencing of $T$. evansi ITS and $T$. vivax TviCatL genes}

The PCR for T. evansi ITS, was performed in $20 \mu$ l of reaction mixture containing $4 \mu \mathrm{l}$ of $5 \times$ Phusion $^{\circ} \mathrm{HF}$ Buffer (1.5 mM MgCl 2 was included in the final concentration), $1.6 \mu \mathrm{l}$ of $200 \mu \mathrm{M}$ dNTPs, $1 \mu \mathrm{l}$ each of $1 \mu \mathrm{M}$ IR1 and IR2 as a final concentration, $0.2 \mu \mathrm{l}$ of Phusion ${ }^{\circ}$ DNA polymerase (BioLabs, New England, USA) and $10.2 \mu \mathrm{l}$ of sterile deionized distilled water. The amplification of ITS was performed for 40 cycles; each cycle consisted of denaturation at $98{ }^{\circ} \mathrm{C}$ for $10 \mathrm{~s}$, annealing at $62{ }^{\circ} \mathrm{C}$ for $30 \mathrm{~s}$ and extension at $72{ }^{\circ} \mathrm{C}$ for $1 \mathrm{~min}$. The entire ITS amplicon was gel-extracted using a QIAamp gel extraction kit (Qiagen), cloned and transformed to chemicallycompetent Escherichia coli (One Shot ${ }^{\ominus}$ Mach1 $^{\mathrm{m}}$; ThermoFisher Scientific) using the $\mathrm{TOPO}^{\circ}$ cloning procedure in accordance with the manufacturer's instructions. After checking the cloned products by colony PCR, 6 clones of ITS were selected for further plasmid DNA purification using a QIAamp Spin Miniprep Kit (Qiagen). Approximately $300 \mathrm{ng} / \mu \mathrm{l}$ of pure plasmid DNA was used for sequencing using a Big Dye Terminator kit (Applied Biosystems, Austin, USA). The cycle sequencing procedure consisted of 30 cycles of denaturation at $96{ }^{\circ} \mathrm{C}$ for $1 \mathrm{~min}$, annealing at $50{ }^{\circ} \mathrm{C}$ for $5 \mathrm{~s}$ and extension at $60{ }^{\circ} \mathrm{C}$ for $2 \mathrm{~min}$. The PCR product was ethanol-precipitated and dissolved in $20 \mu \mathrm{l}$ of $\mathrm{Hi}-\mathrm{Di}$ formamide solution before DNA sequencing. The gene sequence was analysed using an ABI Prism 3100

Table 1 The primers used in the present study

\begin{tabular}{|c|c|c|c|c|c|c|}
\hline Parasite & Method & Primer & Sequence $\left(5^{\prime}-3^{\prime}\right)$ & Target gene & Fragment size (bp) & Reference \\
\hline \multirow[t]{2}{*}{ T. evansi } & KIN-PCR & Kin1 & GCGTTCAAAGATTGGGCAAT & ITS1 & 540 & Desquesnes et al. [20] \\
\hline & & Kin2 & CGCCCGAAAGTTCACC & & & \\
\hline \multirow[t]{2}{*}{ T. evansi } & RoTat 1.2-PCR & ILO7957 & GCCACCACGGCGAAAGAC & RoTat 1.2 VSG & 488 & Urakawa et al. [21] \\
\hline & & ILO8091 & TAATCAGTGTGGTGTGC & & & \\
\hline \multirow[t]{2}{*}{ T. evansi } & ITS-PCR & $\mathrm{IR} 1$ & GCTGTAGGTGAACTTGCAGCAGCTGGATCATT & ITS & 1100 & Da Silva et al. [23] \\
\hline & & IR2 & GCGGGTAGTCCTGCCAAACACTCAGGTCTG & & & \\
\hline \multirow[t]{2}{*}{ T. vivax } & KIN-PCR & Kin1 & GCGTTCAAAGATTGGGCAAT & ITS1 & 300 & Desquesnes et al. [20] \\
\hline & & Kin2 & CGCCCGAAAGTTCACC & & & \\
\hline \multirow[t]{2}{*}{ T. vivax } & TviCatL-PCR & DTO 155 & TTAAAGCTTCCACGAGTTCTTGATGATCCAGTA & Cathepsin L-like & 200 & Cortez et al. [22] \\
\hline & & TviCatL1 & GCCATCGCCAAGTACCTCGCCGA & & & \\
\hline
\end{tabular}


Genetic Analyzer (Applied Biosystems, Carlsbad, CA, USA). Both forward and reverse primers were used to construct a continuous sequence of inserted DNA. In contrast, the TviCatL-PCR products of $T$. vivax were excised from the gel and purified using a QIAamp gel extraction kit (Qiagen), and were subsequently subjected to direct sequencing using a Big Dye Terminator kit, as mentioned above.

\section{Sequence analysis and phylogenetic analysis}

The ITS region of T. evansi (ITS $1+5.8 \mathrm{~S}+\mathrm{ITS} 2 \mathrm{rDNA}$, $\sim 1100 \mathrm{bp}$ ) and the TviCatL-PCR sequences ( 200 bp) of T. vivax were each edited manually to correct possible base calling errors using the BioEdit 7.0 software program [26] and were subsequently joined to reconstruct a $950 \mathrm{bp}$ fragment of the ITS gene and a $160 \mathrm{bp}$ fragment of the TviCatL gene. The consensus sequences were aligned with sequences that were publicly available in the GenBank database using the Clustal X 2.1 software program [27].

Phylogenetic trees were constructed using the neighbourjoining method implemented in the Mega software program (version 6.0) [28]. The best substitution models, as determined by the model test algorithm [29] implemented in the Mega software program were T92 + G and K2 + I for ITS-T. evansi. All sequences generated in this study were deposited in the GenBank database under the accession numbers (LC199490, LC199491, LC198227, LC198229LC198233).

\section{Statistical analysis}

A chi-squared test to investigate the differences in the prevalence of trypanosome infections in the two study areas was performed using the GraphPad Prism software program (GraphPad Software Inc., CA, USA). Cohen's kappa coefficient was calculated using VassarStats: Website for Statistical Computation (http://www.vassarstats. net/kappa.html); the results were interpreted according to a previously described method [30]. The associations between the hematocrit values in the infected and non- infected animals (with each of the trypanosomes), as determined by different diagnostic tests, were analysed using Student's $t$-test. $P$-values were determined using the GraphPad Prism software program (GraphPad Software Inc., CA, USA). $P$-values of $<0.05$ were considered to indicate statistical significance.

\section{Results}

\section{Prevalence of $T$. evansi in camels}

Direct wet blood films showed the presence of trypanosomes in $11 \%(21 / 189)$ of the camel samples, 19 of which showed the typical movement of T. evansi. Two samples showed trypanosomes that moved forward quickly, the characteristic movement pattern of T. vivax [31] (Table 2). However, the concentration of trypanosomes, as measured by MHCT, revealed trypanosomepositivity in $19 \%(36 / 189)$ of the samples (Table 2). Additionally, Giemsa-stained thin blood films revealed trypanosome-positivity in $7 \%(13 / 189)$ of the samples (Table 2). In accordance with the guidelines of Connor \& Van den Bossche [32], which describe the morphology of different trypanosomes in thin blood smears based microscopic observation, T. evansi infection was identified in 10 samples, $T$. vivax was identified in 2 samples, and mixed infection was identified in 1 sample (Fig. 2a-c). Nevertheless, the prevalence estimated by the three tests did not differ to a statistically significant extent.

On the other hand, the KIN-PCR, which targets the ITS1 region, which is conserved in all African trypanosomes, revealed that $37 \%(70 / 189)$ of the samples contained a $540 \mathrm{bp}$ PCR product, indicating the amplification of a Trypanozoon that corresponded to T. evansi (the Tsetse free zone) (Additional file 1: Figure S1). This result was later confirmed. The prevalence in the eastern Nile area was $36 \%(54 / 148)$, while that in the western Nile area was $39 \%(16 / 41)$ (Table 2). No statistical significant difference in the prevalence of trypanosome infection was observed between the two study areas. After that, all of the KIN-PCR-positive samples were further subjected to the $T$. evansi RoTat1.2 VSG species-specific PCR. As a result, a 488 bp PCR product

Table 2 The prevalence of T. evansi, T. vivax and mixed infection in camels with different diagnostic tests

\begin{tabular}{|c|c|c|c|c|c|c|c|c|}
\hline Area & $\begin{array}{l}\text { Giemsa-stained blood } \\
\text { smears }^{\mathrm{a}}\end{array}$ & $\begin{array}{l}\text { Wet blood } \\
\text { filmb }^{b}\end{array}$ & MHCT & $\begin{array}{l}\text { KIN-PCR } \\
\text { T. evansi }\end{array}$ & $\begin{array}{l}\text { RoTat } 1.2 \text { VSG- } \\
\text { PCR }^{\mathrm{C}}\end{array}$ & $\begin{array}{l}\text { KIN-PCR } \\
\text { T. vivax }\end{array}$ & TviCatL-PCR & $\begin{array}{l}\text { Mixed } \\
\text { infection }^{d}\end{array}$ \\
\hline East Nile & $9 \%(13 / 148)$ & $14 \%(20 / 148)$ & $\begin{array}{l}22 \%(33 / \\
148)\end{array}$ & $\begin{array}{l}36 \%(54 / \\
148)\end{array}$ & $59 \%(32 / 54)$ & $\begin{array}{l}25 \%(37 / \\
148)\end{array}$ & $\begin{array}{l}33 \%(49 / \\
148)\end{array}$ & $19 \%(28 / 148)$ \\
\hline $\begin{array}{l}\text { West } \\
\text { Nile }\end{array}$ & $0 \%(0.0 / 41)$ & $3 \%(1 / 41)$ & $7 \%(3 / 41)$ & $39 \%(16 / 41)$ & $56 \%(9 / 16)$ & $24 \%(10 / 41)$ & $24 \%(10 / 41)$ & $15 \%(6 / 41)$ \\
\hline Total & $7 \%(13 / 189)$ & $11 \%(21 / 189)$ & $\begin{array}{l}19 \%(36 / \\
189)\end{array}$ & $\begin{array}{l}37 \%(70 / \\
189)\end{array}$ & $59 \%(41 / 70)$ & $\begin{array}{l}25 \%(47 / \\
189)\end{array}$ & $\begin{array}{l}31 \%(59 / \\
189)\end{array}$ & $18 \%(34 / 189)$ \\
\hline
\end{tabular}

${ }^{\mathrm{a} G i e m s a-s t a i n e d ~ b l o o d ~ s m e a r s: ~} 10$ samples showed typical T. evansi morphology, 2 samples showed typical T. vivax morphology and 1 sample showed mixed infection

${ }^{b}$ Wet blood film: 19 samples showed a typical T. evansi movement pattern while 2 samples showed a typical $T$. vivax movement pattern

'A RoTat 1.2 VSG-PCR was performed on KIN-PCR-positive samples (70 samples)

${ }^{\mathrm{d}}$ Mixed infection was defined by KIN-PCR-positivity for T. evansi and TviCatL-PCR-positivity for T. vivax 

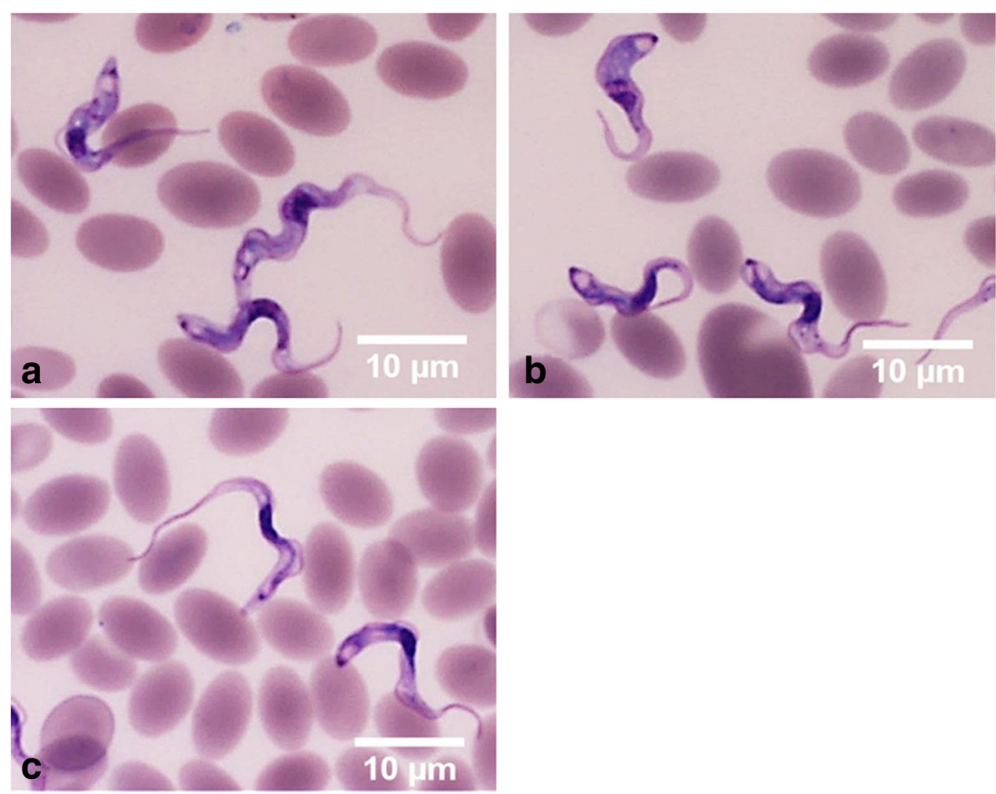

Fig. 2 Light micrographs of Giemsa-stained blood smears from camel samples. a Trypanosoma evansi with a small subterminal kinetoplast at the pointed posterior end, a long free flagellum and a well-developed undulating membrane. b Trypanosoma vivax with a long free flagellum, an inconspicuous undulating membrane, a rounded posterior end and a large terminal kinetoplast. c Mixed infection. Scale-bars: $10 \mu m$

was detected in 59\% (41/70) of the samples (Additional file 2: Figure S2). The prevalence in the eastern Nile area was $59 \%(32 / 54)$ while that in the western Nile area was $56 \%(9 / 16)$ (Table 2).

Confirmation of the $540 \mathrm{bp}$ PCR product of Trypanozoon as T. evansi was achieved by arbitrary selection, cloning and the complete sequencing of the ITS $(\mathrm{ITS} 1+5.8 \mathrm{~S}$
+ ITS2 rDNA) of two positive samples (Additional file 3: Figure S3). The sequence similarity and the phylogenetic analysis confirmed the entity as $T$. evansi by grouping it with other T. evansi strains, in particular, the strains from Egypt, which shares a border with Sudan (Fig. 3). The two sequences were deposited in the GenBank database under the accession numbers LC199490 and LC199491.

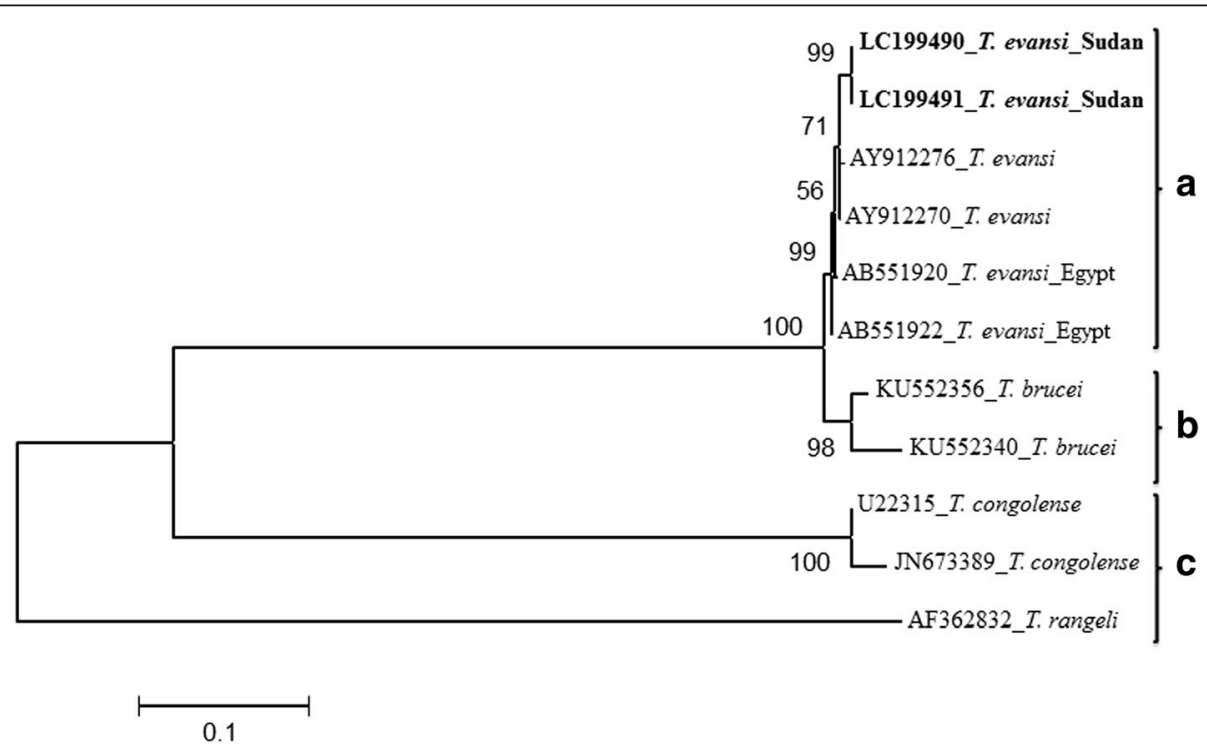

Fig. 3 Confirmation of T. evansi identified in this study by the neighbour-joining phylogenetic tree that shown well clustering with reference sequences of T. evansi. The relationship was determined using the ITS of rRNA gene sequences by neighbour-joining with 1000 bootstraps. T. evansi identified in this study were depicted in bold letters. Trypanosomes sequences from GenBank were shown both by their accession numbers and parasites names. Scale bar used was nucleotide substitutions per site 


\section{Prevalence of $T$. vivax in camels}

Two PCRs were performed to detect $T$. vivax in the present study. First, the KIN-PCR that was used to detect T. evansi $(540 \mathrm{bp}=$ Trypanozoon $)$ generated a $300 \mathrm{bp}$ amplicon, indicating the presence of $T$. vivax in $25 \%(47 / 189)$ of the samples. The prevalence in the samples from the eastern Nile area was 25\% (37/148), while that in the samples from the western Nile area was $24 \%$ (10/41) (Additional file 1: Figure S1; Table 2). Secondly, the TviCatL-species-specific PCR generated a $200 \mathrm{bp}$ amplicon of the $T$. vivax CatL-like gene. This revealed a higher prevalence of $31 \%(59 / 189)$. The prevalence in the eastern Nile area was 33\% (49/148), while that in the western Nile area was 24\% (10/41) (Additional file 4: Figure S4; Table 2). The prevalence detected by the two PCRs did not differ to a statistically significant extent. We further confirmed the identity of the 200 bp-positive samples as $T$. vivax by the direct sequencing of 10 selected samples, as well a Basic Local Alignment Search Tool (BLAST) analysis. Six of these sequences were deposited in GenBank under the accession numbers LC198227, LC198229-LC198233.

\section{Mixed infection with $T$. evansi and $T$. vivax in camels}

The overall prevalence of mixed infection with the two parasites, detected using both the KIN-PCR and the TviCatL-species-specific PCR, was $18 \%$ (34/189). The prevalence in the eastern Nile area was $19 \%(28 / 148)$, while that in the western Nile area was $15 \%(6 / 41)$ (Table 2). The prevalence of mixed infection in the two areas did not differ to a statistically significant extent.

\section{The association between a reduced PCV and anemia}

Because anemia is one of the consequences of trypanosome infections [33] and low a PCV is an indicator of anemia in animals, the mean PCVs in both T. evansiand $T$. vivax-positive animals were significantly low in comparison to their test-negative counterparts (Student's $t$-test, $d f=10, P<0.0001$ ) (Fig. 4).

\section{Agreement between the diagnostic tests}

Sixteen and 13 of the 70 KIN-PCR-positive samples were also found to be positive using wet blood films and thin blood films, respectively. Regarding the negative samples, 3 of the 119 KIN-PCR-negative samples were found to be positive by wet blood films; none were found to be positive using thin blood films (Table 3). There was a fair agreement between the KIN-PCR results and the results of both wet blood films $(\kappa=0.2334)$ and thin blood films $(\mathrm{K}=0.3057)$.

For T. vivax, 40 of the 47 KIN-PCR-positive samples were also found to be positive by the TviCatL-PCR, while 19 of the 142 KIN-PCR-negative samples were found to be positive by the TviCatL-PCR (Table 4).

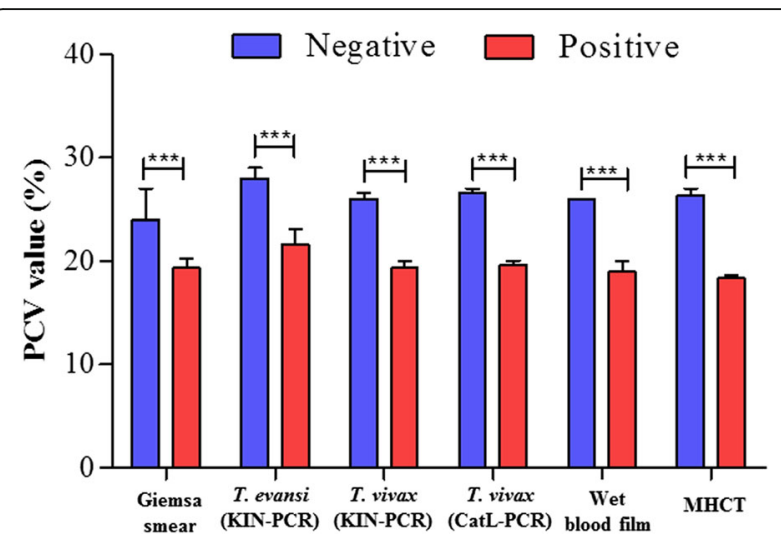

Fig. 4 Comparison of PCV values between trypanosome infected and non-infected camels detected with different diagnostic tests. Values are mean $\pm S D$. The significant difference by Student's t-test (***P $<0.0001)$

There was substantial agreement between the KIN-PCR and the TviCatL-PCR results $(\kappa=0.6608)$.

\section{Discussion}

Ever since the first report of camel trypanosomosis in 1904 [9] and until 2011 [15], T. evansi has been the only reported causative agent of the disease. In the present study, we documented, for the first time, that $T$. vivax was highly prevalent in Sudan. The parasite was detected in $31 \%(59 / 189)$ of the camels in the present study. This finding is supported by the detection of the parasite by various parasitological tests and confirmed by the detection and identification of its DNA by PCRs and sequencing analysis. Thus, we argue that $T$. vivax is a newly emerging cause of the disease in the country. This argument is strongly supported by the study of Salim et al. [15] who only detected T. evansi in the screening of 687 camels from geographically different areas of the country using molecular detection methods. This may possibly be attributed to various causes, including, but not limited to, climate change, limited access to veterinary services and follow-up, and the displacement of people and their animals from the Blue Nile State in the southeastern part of the country (a Tsetse-endemic area) and from the southern Kordofan State to the northern part of the country, due to a conflict that has taken place since 2011 [34].

Table 3 The detection of T. evansi in camels. The KIN-PCR results were cross-tabulated with those of wet blood films and thin blood films

\begin{tabular}{|c|c|c|c|c|c|c|}
\hline & \multicolumn{2}{|c|}{ KIN-PCR } & \multicolumn{2}{|c|}{ Wet blood film } & \multicolumn{2}{|c|}{ Thin blood film } \\
\hline & & & $(+)$ & $(-)$ & $(+)$ & $(-)$ \\
\hline \multirow[t]{2}{*}{ T. evansi } & $(+)$ & 70 & 16 & 54 & 13 & 57 \\
\hline & $(-)$ & 119 & 3 & 116 & 0 & 119 \\
\hline
\end{tabular}


Table 4 The detection of T. vivax in camels

\begin{tabular}{llllll}
\hline & \multicolumn{1}{l}{ KIN-PCR } & & & \multicolumn{2}{l}{ TviCatL-PC } \\
& & & & $(+)$ & $(-)$ \\
\hline T. vivax & $(+)$ & 47 & 40 & 7 \\
& $(-)$ & 142 & 19 & 123
\end{tabular}

The KIN-PCR results were cross-tabulated with the TviCalL-PCR results

The detection of trypanosomes in 7\% (13/189) of the camel samples using Giemsa-stained blood smears is compatible with the prevalence reported by Ali et al. [16], which was 6\% in Sudan and 6.5\% in Ethiopia [35, 36]. However, it was higher than the prevalence reported in the previous year, which was $2 \%$ in Ethiopia [37], 2.3\% in Kenya [38] and $2.5 \%$ in Nigeria [39]. This could be due to the differences in animal husbandry and management practices, seasonal effects, or the study design. It is worth mentioning that all of the Giemsa-positive animals were from the eastern Nile area. No animals from the western Nile area were found to be positive. This might be because the animals from the western Nile area $(n=41)$ were apparently healthy and well fed since they had been prepared to slaughter for human consumption, which resulted in their parasitemia being lower than the detectable level. This could also be why the other parasitological technique showed the same pattern of detection within the two areas.

The prevalence of 19\% (36/189) obtained using MHCT was higher than that in a previous study which reported that the prevalence in eastern Sudan was 5.4\% [12]. The prevalence detected by wet blood films was $11 \%$ (21/189). This was comparable to a previous study, which reported that the prevalence was $14.1 \%$ [13]. The high parasitological prevalence might also be due to the spread of drug resistance, which was reported in previous studies [13, 40].

General, Giemsa-stained blood smears and wet blood films have been found to be useful for recognising and differentiating $T$. evansi and $T$. vivax based on their characteristic morphology and movement patterns. However, it is difficult to differentiate between the parasites using MHCT because of the massive movement of the parasites within the small area of the buffy coat within the capillary tube.

The detection of T. evansi and T. vivax in the sampled camels using less-sensitive parasitological examination methods confirmed the results and provided a guide to the molecular prevalence of the parasites. This proved that molecular detection outperformed conventional parasitological techniques by identifying parasites at the species level with $100 \%$ credibility and revealed high prevalence and mixed infection with higher resolution (see Results). For instance, the PCRs performed using universal primers to simultaneously detect and differentiate the T. brucei group, T. congolense and T. vivax by amplifying ITS1 using the so-called KIN-multi-species PCR procedure [20] revealed that 37\% (70/189) of the samples were positive for Trypanozoon. This rate was significantly higher than the prevalence detected using Giemsa-stained thin blood smears (7\%; 13/189), wet blood films (11\%; 21/189) and MHCT (19\%; 36/189). The 70 Trypanozoon-positive samples were further confirmed to be $T$. evansi-positive by a RoTat 1.2 VSGspecies specific PCR and by a sequencing analysis of the ITS region of some of the KIN-PCR-positive samples. However, while the RoTat 1.2 VSG-species-specific PCR detected 41 (59\%) positive samples (among the 70 Trypanozoon-positive samples), the KIN-PCR detected an additional 29 positive samples. This could be attributed to the limitation of the RoTat 1.2 VSG-PCR in detecting RoTat 1.2 VSG-negative T. evansi, which has been previously reported in Sudanese camels [15]. Thus, these 29 negative samples were regarded as $T$. evansi type B $[15,41]$.

Similarly, KIN-PCR simultaneously detected T. vivax in $25 \%(47 / 189)$ of the samples. The TviCatL-speciesspecific further confirmed the result and revealed a higher prevalence of $31 \%$. Although the TviCatL-PCR has been shown to have greater sensitivity than the KINPCR in detecting $T$. vivax, we observed substantial agreement between the two tests $(\kappa=0.6608)$. Conversely, the KIN-PCR has been reported to have limited ability in the detection of $T$. vivax $[20,25,42]$, because it is a very diverse parasite, with three main groups of isolates: (i) East African; (ii) West African; and (iii) South American isolates [22]. Thus, T. vivax may be difficult to detect using a single PCR. However, in the present study, comparable numbers of samples from camels in Sudan were found to be $T$. vivax-positive by the KIN and TviCatL PCRs. Thus, additional research should be conducted to verify the possible diversity of $T$. vivax in Sudan. We have also reported the mixed infection between $T$. evansi and T. vivax in $18 \%(34 / 189)$ which is higher than that reported by Birhanu et al. in Ethiopia [43].

The overall prevalence of $T$. evansi and $T$. vivax, as detected using parasitological techniques (Giemsa thin blood smears, wet blood smears and MHCT), was significantly lower in comparison to the prevalence detected by molecular tests (KIN-PCR for T. evansi and KIN-PCR and TviCatL-PCR for $T$. vivax $)(P<0.05)$. In all the infected animals, the PCVs were lower than the PCVs in non-infected animals. This was also clearly demonstrated in T. vivax-infected camels. Similar results were obtained in Ethiopia by Birhanu et al. [43]. In some of the individual camels infected with $T$. evansi or $T$. vivax, the PCV was as low as $9 \%$, while PCVs of as low as $24 \%$ were measured in some apparently healthy animals that were in good physical condition. This indicates that caution must be exercised when measuring the PCV to avoid a misdiagnosis. 
The paradigm that camel trypanosomosis is caused by a single parasite species (T. evansi) is no longer valid after our detection of $T$. vivax, as a second causative agent of the disease. Consequently, these findings should alert veterinary authorities of the need to safeguard approximately 5 million camels in Sudan. Ultimately, the disease caused by $T$. vivax has a different clinical presentation with high pathogenicity [44], which might cause higher morbidity and mortality rates alongside $T$. evansi, which on some occasions is also known to be highly pathogenic in camels. It is worth mentioning that $T$. vivax infection is also transmitted mechanically, as occurs in the case of T. evansi, by several Tabanids and a range of biting flies [45, 46]. This makes the transmission and the spread of infection possible in a wide range of camel populations in Sudan. In the same context, $T$. vivax was reported to have spread widely, as far as North Sudan, which is located hundreds of kilometres from the tsetse belt, a region that includes camel breeding areas [47].

In Ethiopia, which shares a border with eastern Sudan, Fikru et al. [37] recently confirmed T. vivax in camels. This suggests that the emergence of $T$. vivax infection will be a future regional challenge in at least two countries, with a total camel population of over 6 million. Similarly, Mbaya et al. [48] reported T. vivax in camels in Nigeria, which is in western Africa.

\section{Conclusions}

We documented, for the first time, the high prevalence of T. vivax in camels from eastern Sudan, which, until five years previously, was reported to be free of the parasite. The presence of T. vivax in camels detected in this study is a challenge in the choice of diagnostic approaches, particularly serology and PCRs. Furthermore, the findings should alert veterinary authorities of the need to look carefully for an effective combination that can be used in the treatment of this devastating disease, which has been newly emerged in the area. The finding that camel trypanosomosis caused by $T$. vivax or mixed infection with $T$. evansi is highly prevalent in the country suggests the need for stringent control policies and the establishment of measures to help prevent the spread of the parasites. We also recommend that the disease status is updated throughout the country, as we anticipate that there will have been a marked change in the situation.

\section{Additional files}

Additional file 1: Figure S1. Agarose gel electrophoresis (2\%) with ethidium bromide staining of field isolates of T. evansi and T. vivax. The DNA was amplified with a KIN-PCR (kin1 and kin2 primers). Lane M: 100-bp marker; Lane 1: negative control; Lane 2: positive control (T. evansi); Lanes 3-7 and 9-11: positives for T. evansi (540 bp); Lanes 8 and 12: negative samples. T. vivax, Lanes 4, 5, 7, 8 and 11: positives for T. vivax (300 bp); Lanes 3, 6, 9 and 12: negative samples. Mixed infection, Lanes 4, 5, 7 and 11. The extra-bands were non-specific. (TIF $110 \mathrm{~kb}$ )
Additional file 2: Figure S2. Agarose gel electrophoresis (2\%) with ethidium bromide staining of field isolates of T. evansi (obtained in the field). The DNA was amplified with a RoTat 1.2 VSG-PCR. Lane M: 100-bp marker; Lane 1: negative control; Lane 2: positive control (T. evansi); Lanes 4-8 and 10-11: positives for T. evansi (488 bp); Lanes 3 and 9: negative samples. (TIF $86 \mathrm{~kb}$ )

Additional file 3: Figure S3. Agarose gel electrophoresis (1.5\%) with ethidium bromide staining of field isolates of T. evansi. DNA was amplified with an ITS-PCR (IR1 and IR2 primers). Lane M: 100-bp marker; Lane 1: negative control; Lane 2: positive control (T. evansi); Lanes 3-6: positives for T. evansi (1.1 kbp); Lanes 7 and 8: negative samples. The extra-bands were non-specific. (TIF $144 \mathrm{~kb}$ )

Additional file 4: Figure S4. Agarose gel electrophoresis (2\%) with ethidium bromide staining of field isolates of T. vivax. DNA was amplified with a TviCatL-PCR (DTO155 and TviCatL1 primers). Lane M: 100-bp marker; Lane 1: negative control; Lanes 2-7 and 9-15: positives for T. vivax (200 bp); Lane 16: positive control (T. vivax); Lane 8: negative sample. The extra-bands were non-specific. (TIF $122 \mathrm{~kb}$ )

\section{Abbreviations}

BLAST: Basic local alignment search tool; ITS: Internal transcribed spacer; MHCT: Microhematocrit centrifugation technique; OIE: Office international des epizooties; PCV: Packed cell volume; K: Kappa value

\section{Acknowledgments}

We would like to express our gratitude to the staff of the Tumbool Camel Research Center, Animal Resources Research Corporation. Ministry of Livestock, Fisheries and Rangelands, Khartoum, Sudan and the staff of the Alshowak Camel Research Centre, Faculty of Veterinary Medicine, University of Khartoum, Khartoum, Sudan for their help during our field missions. We would also like to acknowledge Dr Khitma Elmalik of University of Khartoum, Sudan, for the fruitful discussion.

\section{Funding}

This study was financially supported by the Ministry of Higher Education and Scientific Research, Republic of Sudan (Grant No. SRI-VS-2015-71933). Additional funding was received from the "International Collaborative Research Program for Tackling the NTD (Neglected Tropical Diseases) Challenges in African Countries" from the Japan Agency for Medical Research and Development (AMED).

\section{Availability of data and materials}

All data generated or analysed during this study are included in the article and its additional files. The newly generated sequences were deposited in the GenBank database under the accession numbers LC199490, LC199491, LC198227 and LC198229-LC198233.

\section{Authors' contributions}

EM designed the study, carried out the field survey, the parasitological analysis and DNA extraction, the PCRs, the sequencing analysis, the data analysis, the statistical analysis and interpreted the data. BS carried out the field survey, the parasitological analysis, helped in the DNA extraction and performed the RoTat 1.2 PCR-based phylogenetic analysis. MAH carried the field survey, the parasitological analysis, and helped in the DNA extraction. PM helped in the PCRs. EAE, AOB and GEM jointly supervised the methodological aspects related to the fieldwork. KS, XX and NI supervised the aspects of the study that were related to the molecular work. EM and BS jointly drafted the paper. All authors read and approved the final manuscript.

\section{Competing interests}

The authors declare that they have no competing interests.

\section{Consent for publication}

Not applicable.

\section{Ethics approval and consent to participate}

Permission was obtained according to the standards of animal experimentation at the Obihiro University of Agriculture and Veterinary Medicine (Approval No. 28-46). 


\section{Publisher's Note}

Springer Nature remains neutral with regard to jurisdictional claims in published maps and institutional affiliations.

\section{Author details \\ 'Department of Pathology, Parasitology and Microbiology, College of Veterinary Medicine, Sudan University of Science and Technology, P.O. Box 204, Khartoum, Sudan. ${ }^{2}$ National Research Center for Protozoan Diseases, Obihiro University of Agriculture and Veterinary Medicine, Obihiro, Hokkaido 080-8555, Japan. ${ }^{3}$ Faculty of Veterinary Medicine, University of Khartoum, P.O Box 32, Khartoum-North, Sudan. "Research Center for Global Agromedicine, Obihiro University of Agriculture and Veterinary Medicine, Obihiro, Hokkaido 080-8555, Japan. ${ }^{5}$ Tsetse and Trypanosomosis Control Department, Central Veterinary Research Laboratory, Animal Resources Research Corporation, Ministry of Livestock, Fisheries and Rangelands, Khartoum, Sudan. ${ }^{6}$ Obihiro University of Agriculture and Veterinary Medicine, Obihiro, Hokkaido, 080-8555, Japan}

\section{Received: 23 December 2016 Accepted: 28 March 2017}

\section{Published online: 13 April 2017}

\section{References}

1. Joshi PP, Shegokar VR, Powar RM, Herder S, Katti R, Salkar HR, et al. Human trypanosomiasis caused by Trypanosoma evansi in India: the first case report. Am J Trop Med Hyg. 2005;73:491-95.

2. Van Vinh Chau N, Buu Chau L, Desquesnes M, Herder S, Phu Huong Lan N, Campbell $\mathrm{J}$, et al. A clinical and epidemiological investigation of the first reported human infection with the zoonotic parasite Trypanosoma evansi in Southeast Asia. Clin Infect Dis. 2016;62:1002-8.

3. Desquesnes M, Dargantes A, Lai DH, Lun ZR, Holzmuller P, Jittapalapong S Trypanosoma evansi and surra: a review and perspectives on transmission, epidemiology and control, impact, and zoonotic aspects. Biomed Res Int. 2013;2013:321237.

4. Malik KH, Mahmoud MM. Trypanosomiasis. Sudan J Vet Sci Anim Husb. 1978;18:47-57.

5. Shommein AM, Osman AM. Diseases of camels in the Sudan. Rev Sci Tech Off Int Epiz. 1987:6:481-6.

6. Chaudhary $\mathrm{ZI}$, lqbal J. Incidence, biochemical and haematological alterations induced by natural trypanosomosis in racing dromedary camels. Acta Trop. 2000;77:209-13.

7. Mahmound MM, Gray AR. Trypanosomosis due to T. evansi (Istell, 1885: Balbiani, 1885). A review of recent research. Trop Anim Health Prod. 1988; 12:35-47.

8. Büscher P. Diagnosis of African trypanosomiasis. In: Magez S, Radwanska M, editors. Trypanosomes and Trypanosomiasis. Wien: Springer; 2014. p. 189-216.

9. Elkarib AE. Animal trypanosomiasis in Sudan. Sudan J Vet Sci Animl Husb. 1961;2:39-46.

10. Boid R, el-Amin EA, Mahmoud MM, Luckins AG. Trypanosoma evansi infections and antibodies in goats, sheep and camels in the Sudan. Trop Anim Health Prod. 1981;13:141-6.

11. Dafaalla E. A study on incidence of camel trypanosomosis in Kassala province, Sudan. Sud Vet Res. 1988:8:35-8.

12. Elamin EA, el Bashir MO, Saeed EM. Prevalence and infection pattern of Trypanosoma evansi in camels in mid-eastern Sudan. Trop Anim Health Prod. 1998;30:107-14.

13. Babeker $E_{\iota}$ Hassab Elrasoul $Y$. Incidence and treatment of camel trypanosomosis (Guffar) in west Omdurman in Sudan. J Vet Adv. 2014;4: 582-93.

14. Aradaib IE, Majid AA. A simple and rapid method for detection of Trypanosoma evansi in the dromedary camel using a nested polymerase chain reaction. Kinetoplastid Biol Dis. 2006;5:1

15. Salim B, Bakheit MA, Kamau J, Nakamura I, Sugimoto C. Molecular epidemiology of camel trypanosomiasis based on ITS1 rDNA and RoTat 1.2 VSG gene in the Sudan. Parasit Vectors. 2011:4:31.

16. Ali NO, Croof HI, Abdalla HS. Molecular diagnosis of Trypanosoma evansi infection in Camelus dromedarius from Eastern and Western regions of the Sudan. Emirates J Food Agric. 2011;23:320.

17. Murray M, Murray $P$, Mclntyre W. An improved parasitological technique for the diagnosis of African trypanosomiasis. Rrans R Soc Trop Med Hyg. 1977; 71:325-6.
18. Woo PT. The haematocrit centrifuge technique for the diagnosis of African trypanosomiasis. Acta Trop. 1970:27(4):384-6.

19. OIE. Trypanosoma evansi infection (Surra). In: Terrestrial Manual. 2012 Chapter. 2. 1. 17.

20. Desquesnes M, McLaughlin G, Zoungrana A, Dávila AM. Detection and identification of Trypanosoma of African livestock through a single PCR based on internal transcribed spacer 1 of rDNA. Int J Parasitol. 2001;31:610-4.

21. Urakawa T, Verloo D, Moens L, Büscher P, Majiwa PA. Trypanosoma evansi: cloning and expression in Spodoptera fugiperda insect cells of the diagnostic antigen RoTat1. 2. Exp Parasitol. 2001;99:181-9.

22. Cortez AP, Rodrigues AC, Garcia HA, Neves L, Batista JS, Bengaly Z, et al. Cathepsin L-like genes of Trypanosoma vivax from Africa and South America - characterization, relationships and diagnostic implications. Mol Cell Probes. 2009;23:44-51

23. Da Silva FM, Noyes H, Campaner M, Junqueira AC, Coura JR, Anez N, et al. Phylogeny, taxonomy and grouping of Trypanosoma rangeli isolates from man, triatomines and sylvatic mammals from widespread geographical origin based on SSU and ITS ribosomal sequences. Parasitology. 2004;129:549-61.

24. Khuchareontaworn S, Singhaphan P, Viseshakul N, Chansiri K. Genetic diversity of Trypanosoma evansi in buffalo based on internal transcribed spacer (ITS) regions. J Vet Med Sci. 2007:69:487-93.

25. Laohasinnarong D, Thekisoe OM, Malele I, Namangala B, Ishii A, Goto Y, et al. Prevalence of Trypanosoma sp. in cattle from Tanzania estimated by conventional PCR and loop-mediated isothermal amplification (LAMP). Parasitol Res. 2011;109:1735-9.

26. Hall TA. BIOEDIT: A user-friendly biological sequence alignment editor and analysis program for Windows 95/98/NT. In: Nucleic Acids Symposium Series. 1999. p. $95-8$.

27. Thompson JD, Gibson TJ, Plewniak F, Jeanmougin F, Higgins DG. The CLUSTAL_X windows interface: flexible strategies for multiple sequence alignment aided by quality analysis tools. Nucleic Acids Res. 1997;25:4876-82.

28. Tamura K, Stecher G, Peterson D, Filipski A, Kumar S. MEGA6: Molecular Evolutionary Genetics Analysis version 6.0. Mol Biol Evol. 2013;30:2725-9.

29. Posada D. jModelTest: phylogenetic model averaging. Mol Biol Evol. 2008; 25:1253-6.

30. Viera AJ, Garrett JM. Understanding interobserver agreement: the kappa statistic. Fam Med. 2005;37:360-3.

31. Uilenberg G. A Field Guide for the Diagnosis, Treatment and Prevention of African Animal Trypanosomosis. Rome: Food \& Agriculture Organization; 1998.

32. Connor RJ, Bossche VD. African animal trypanosomoses. In: Coetzer JAW, Tustin RC, editors. Infectious Diseases of Livestock, vol. 12. Cape Town: Oxford University Press; 2004. p. 251-9.

33. Van den Bossche P. Some general aspects of the distribution and epidemiology of bovine trypanosomosis in southern Africa. Int J Parasitol. 2001;31:592-8.

34. South Kordofan \& Blue Nile. Population Movements Fact Sheet. 2014. http:// reliefweb.int/sites/reliefweb.int/files/resources/South\%20Kordofan\%20and \%20Blue\%20Nile\%20Population\%20Movements\%20Fact\%20 Sheet\%20\%2019\%20May\%202014.pdf. Accessed 10 Dec 2016.

35. Abebe W. Practices and major health problems of cames in the Ogaden, Ethiopia. Eura J Agric Environ Sci. 1991;8:633-42

36. Hailu D. The prevalence of camel trypanosomosis in the salt convey routes of Afar-Tigrai. DVM Thesis, FVM, Addis Abeba University Debre Zeit, Ethiopia. 2000.

37. Fikru R, Andualem Y, Getachew T, Menten J, Hasker E, Merga B, et al. Trypanosome infection in dromedary camels in eastern Ethiopia: prevalence, relative performance of diagnostic tools and host related risk factors. Vet Parasitol. 2015;211:175-81.

38. Ngaira JM, Njagi EN, Ngeranwa JJ, Olembo NK. PCR amplification of RoTat 1.2 VSG gene in Trypanosoma evansi isolates in Kenya. Vet Parasitol. 2004; 120:23-33.

39. Egbe-Nwiyi T, Chaudhry S. Trypanosomiasis: prevalence and pathology of camel of arid zone of north eastern Nigeria. Pak Vet J. 1994;14:24.

40. El Rayah IE, Kaminsky R, Schmid C, El Malik KH. Drug resistance in Sudanese Trypanosoma evansi. Vet Parasitol. 1999;80:281-7.

41. Birhanu H, Gebrehiwot T, Goddeeris BM, Büscher P, Van Reet N. New Trypanosoma evansi type B isolates from Ethiopian dromedary camels. PLoS Negl Trop Dis. 2016:10, e0004556.

42. Njiru Z, Constantine C, Guya S, Crowther J, Kiragu J, Thompson R, Dávila AM. The use of ITS1 rDNA PCR in detecting pathogenic African trypanosomes. Parasitol Res. 2005;95:186-92. 
43. Birhanu H, Fikru R, Said M, Kidane W, Gebrehiwot T, Hagos A, et al. Epidemiology of Trypanosoma evansi and Trypanosoma vivax in domestic animals from selected districts of Tigray and Afar regions, Northern Ethiopia. Parasit Vectors. 2015:8:212.

44. Galiza G, Garcia H, Assis A, Oliveira D, Pimentel L, Dantas A, et al. High mortality and lesions of the central nervous system in trypanosomosis by Trypanosoma vivax in Brazilian hair sheep. Vet Parasitol. 2011;182:359-63.

45. Sinshaw A, Abebe G, Desquesnes M, Yoni W. Biting flies and Trypanosoma vivax infection in three highland districts bordering Lake Tana, Ethiopia. Vet Parasitol. 2006;142:35-46.

46. Morrison LJ, Vezza L, Rowan T, Hope JC. Animal African trypanosomiasis: time to increase focus on clinically relevant parasite and host species. Trends Parasitol. 2016;32:599-607.

47. Ahmed SK, Rahman AH, Hassan MA, Salih EM, Paone M, Cecchi G. An atlas of tsetse and bovine trypanosomosis in Sudan. Parasit Vectors. 2016:9:194.

48. Mbaya A, Ibrahim U, Apagu S. Trypanosomosis of the dromedary camel (Camelus dromedarius) and its vectors in the tsetse-free arid zone of North Eastern, Nigeria. Niger Vet J. 2010;31.

Submit your next manuscript to BioMed Central and we will help you at every step:

- We accept pre-submission inquiries

- Our selector tool helps you to find the most relevant journal

- We provide round the clock customer support

- Convenient online submission

- Thorough peer review

- Inclusion in PubMed and all major indexing services

- Maximum visibility for your research

Submit your manuscript at www.biomedcentral.com/submit
Biomed Central 